July 2001

\title{
The Response of Term Rates to Monetary Policy Uncertainty*
}

\begin{abstract}
This paper shows that greater uncertainty about monetary policy can lead to a decline in nominal interest rates. In the context of a limited participation model, monetary policy uncertainty is modeled as a mean-preserving spread in the distribution for the money growth process. This increase in uncertainty lowers the yield on short-term maturity bonds because the household sector responds by increasing liquidity in the banking sector. Long-term maturity bonds also have lower yields but this decrease is a result of the effect that greater uncertainty has on the nominal intertemporal rate of substitution - which is a convex function of money growth. These predictions are broadly supported by the data: the conditional variance of monetary policy shocks identified from a conventional monetary VAR negatively affects the yields of federal funds, and the three and six-month treasury bills.
\end{abstract}

- JEL Classification: E4, E5, E2

- Keywords: limited participation, term structure, time-varying uncertainty.

Oscar Jordá and Kevin D. Salyer

Department of Economics

U. C. Davis

One Shields Ave.

Davis, CA 95616-8578

Contact Information:

Jordá: (530) 752 7021; E-mail: ojorda@ucdavis.edu

Salyer: (530) 752 8359; e-mail: kdsalyer@ucdavis.edu

${ }^{*}$ We thank Tom Mayer for his encouragement and suggestions. 


\section{Introduction}

The current generation of quantitative macroeconomic models, such as those based on the real business cycle paradigm, invariably cast the analysis within a stochastic environment in which the first moments of policy variables constitute the almost exclusive object of interest. In this literature, beginning with the Lucas tradition that emphasized the distinction between unanticipated and anticipated monetary policy and continuing with modern extensions that introduce various real and nominal rigidities (sticky prices, sticky wages, and limited participation models, for example), there are few examples that study the impact that the second (and higher) moments of policy variables have on economic activity and welfare. This paper broadens the analysis of macroeconomic policy by investigating how monetary policy uncertainty affects one important aspect of the macroeconomy: nominal yields on risk-free bonds.

We are not the first to point out the paucity of research that examines the consequences of policy uncertainty. Obstfeld and Rogoff (2000) highlight the scant attention that policy uncertainty receives in open economy, macroeconomic policy analysis. While concerns about uncertainty of monetary policy are reflected in popular discussions of policy transparency and policy risk, the theoretical neglect of these issues is primarily driven by a key technical consideration: the solution of stochastic general equilibrium macroeconomic models typically involves a linear approximation that implies certainty equivalence in equilibrium. Obstfeld and Rogoff depart from certainty equivalence by assuming that the exogenous variables in the model have lognormal distributions. This particular distributional assumption allows them 
to obtain closed form solutions. Our analysis also requires that we make distributional assumptions to find exact solutions to the economy but these take the form of a discretestate Markov process for monetary policy. Moreover, the transition probability matrix of this Markov process is appropriately parametrized to study the effects of time-varying uncertainty. $^{1}$

Few papers outside the finance literature have successfully explained the variation in the term-structure of interest rates with a modern equilibrium macroeconomic model. For example, den Haan's (1995) analysis predicts a yield curve that is essentially flat. A notable exception is that of Evans and Marshall (1998) who find that a limited participation model of monetary nonneutrality is broadly consistent with empirical regularities in the term structure. A limited participation model ${ }^{2}$ is an attractive environment for an investigation of policy uncertainty on term-structure relations because of three important properties: (1) the channel of monetary policy transmission is captured through the traditional mechanism of liquidity affecting interest rates which, in turn, affect real activity; (2) agent's savings decisions, which in part determine the supply of funds in the loan market, are made before the state of the world is known. Consequently, time varying uncertainty in monetary policy may create an endogenous response in the loan market which will be reflected in interest rates; and (3) nominal interest rates are affected by both Fisherian and liquidity factors. Subse-

\footnotetext{
${ }^{1}$ That is, Obstfeld and Rogoff (2000) focus on the unconditional variance of money growth so that their analysis is one of comparative dynamics. In contrast, the analysis presented here studies the effects of changes in uncertainty within a particular economy.

2 This monetary model is also a departure from the Obstfeld and Rogoff (2000) analysis which generates a demand for money by placing real balances in the utility function. Since their focus is on price setting behavior and nominal rigidities, a money-in-the-utility fuction approach is reasonable. However, since our emphasis is on the term structure, a richer model of interest rates is required.
} 
quently, changes in the second moment of monetary policy (which in our model is described by a simple money growth rule) may affect interest rates through one or both factors. The few previous studies that have examined the effects of time-varying uncertainty (e.g. Lee, 1995; Hodrick, 1989; and Dellas and Salyer, 2001) used a simple cash-in-advance framework so that nominal interest rates are not affected by liquidity considerations. In addition, the environments investigated in these papers were either exchange economies or they insulated production from monetary uncertainty so that the interaction between uncertainty, output, and interest rates could not be analyzed.

The main results in our paper can be summarized as follows. The model predicts that increases in monetary policy uncertainty will produce a generalized decline in interest rates for all maturities. This prediction has different explanations that depend on the maturity of the bond: at the very short end of the maturity spectrum, the endogenous response of savings (i.e. funds placed in the banking sector) to greater uncertainty results in more liquidity in the lending market, thus lowering the nominal yield. At longer maturities, the decline in rates because of greater uncertainty is due to the fact that the marginal utility of a dollar is a convex function of money growth, which causes a fall in the certainty equivalence of a dollar in the future. The predictions for term premia are indeterminate since they depend on risk aversion and the persistence of monetary policy.

The empirical results support these predictions. We use Evans and Marshall's (1998) monetary VAR to identify the monetary policy innovation series which is then fitted with a GARCH $(1,1)$ process to characterize its time-varying volatility. The dynamic responses of 
nominal interest rates to variations in this time-varying volatility are negative, just as the model predicts. The lack of an appreciable effect of uncertainty on term premia is consistent with the high degree of inertia in monetary policy setting. The remainder of the paper is organized as follows. Section 2 presents the model, whose solution is described in Section 3. Section 4 measures the effect of monetary policy uncertainty empirically and Section 5 presents our conclusions.

\section{The Model}

The model that we employ for our analysis is closely related to that presented in Christiano, Eichenbaum, and Evans (1997), hence, expositional comments will be brief. The setup is a standard limited participation framework with four sectors; firms, households, financial intermediaries and the monetary authority. Moreover, the interaction between these sectors is characterized by three factors: (1) households determine the fraction of savings placed in the banking sector before they know the current monetary growth rate state; (2) firms must borrow funds to pay their labor costs; and (3) the monetary transfer is distributed solely to the financial intermediaries. The details and implications of this environment are provided below.

\subsection{Firms}

Firms in the model are identical and produce output via a constant returns to scale technology:

$$
y_{t}=h_{t}^{1-\alpha}
$$


For expositional simplicity and to concentrate on the liquidity channel, note that we have assumed that capital is fixed at the value of one in all periods. ${ }^{3}$ Consequently, firms purchase labor from households with the nominal wage given by $W_{t}$. Firms must pay for labor services in advance of production with the wage bill financed via loans from the financial intermediaries. Therefore, the cost of production is given by $R_{t} W_{t} h_{t}$, where $R_{t}$ is the (gross) interest rate on loans from the banking sector, which are repaid at the end of the period. The necessary condition associated with the optimal choice for labor is the familiar:

$$
R_{t} \frac{W_{t}}{P_{t}}=(1-\alpha) h_{t}^{-\alpha}
$$

As can be clearly seen in equation (2), nominal interest rates will affect labor costs and, therefore, can influence economic activity.

\subsection{Households}

Households decisions are more complicated and are made sequentially as information becomes available. Specifically, it is assumed that agents must allocate their nominal wealth at the beginning of the period between funds to be used for consumption (denoted $c_{t}$ ) in the goods market (where agents face a cash-in-advance constraint) and savings, $I_{t}$, placed in the banking sector. This portfolio decision is made before the current state of the world, i.e. the monetary growth rate state, is known. After the funds are allocated to the banking sector, agents learn of the monetary growth rate state and, with this resolution of uncertainty, all prices are known. Consumption and labor decisions are then made. Note that the funds

\footnotetext{
${ }^{3}$ The capital stock is owned by the households; hence firm profits represent the returns to capital. These are distributed to households at the end of the period.
} 
allocated for consumption at the beginning of the period are augmented by current labor income; this total is used to finance consumption (the cash-in-advance constraint is binding). Households then receive profits from firms (denoted $\zeta_{t}$ ), the income from deposits made to the banking sector, and bank profits made from lending new money, $T_{t}$, received from the monetary authorities (described in detail below).

The households' maximization problem can be written in the form of the following dynamic programming problem:

$$
V\left(\frac{M_{t-1}}{P_{t}}\right)=\max _{I_{t}} E_{t-1}\left\{\max _{\left(c_{t}, h_{t}, M_{t}\right)}\left[U\left(c_{t}, 1-h_{t}\right)+\beta E_{t}\left(V\left(\frac{M_{t}}{P_{t+1}}\right)\right)\right]\right\}
$$

subject to:

$$
\begin{gathered}
P_{t} c_{t} \leq M_{t-1}-I_{t}+W_{t} h_{t} \\
M_{t}=\left(M_{t-1}-I_{t}+W_{t} h_{t}-P_{t} c_{t}\right)+\zeta_{t}+R_{t}\left(T_{t}+I_{t}\right)
\end{gathered}
$$

The time subscripts on the expectations operators are used to denote the information set relevant at the time of decision. Equation (4) is the cash-in-advance constraint while equation (5) is the budget constraint. The necessary conditions associated with this maximization problem are:

$$
\begin{gathered}
E_{t-1}\left[\frac{U_{c, t}}{P_{t}}-R_{t} \beta E_{t}\left(\frac{U_{c, t+1}}{P_{t+1}}\right)\right]=0 \\
U_{l, t}=U_{c, t} \frac{W_{t}}{P_{t}}
\end{gathered}
$$

where $U_{c, t}$ and $U_{l, t}$ denote the marginal utilities of consumption and leisure, respectively. Equation (6) is the hallmark of the limited participation model and represents the fact that 
the one-period nominal interest rate will be, on average, equal to the nominal intertemporal marginal rate of substitution. However, $R_{t}$ will depart from this term due to unanticipated changes in liquidity. Consequently, the short term nominal interest rate is affected by Fisherian (i.e. the intertemporal marginal rate of substitution) and liquidity factors. The second equation represents the traditional labor-leisure trade-off.

\subsection{Financial Intermediaries}

Each period, financial intermediaries in the economy issue loans, $L_{t}$, in order to maximize profits. It is assumed that there are no costs associated with making loans so that all funds are inelastically supplied. That is,

$$
L_{t}=T_{t}+I_{t}
$$

As noted before, $T_{t}$ denotes the monetary transfer from the central bank. The assumption that the monetary injection enters into the economy via the banking sector is another distinguishing characteristic of the limited participation model and is an attempt to capture the asymmetric effects that open market operations have on households and financial intermediaries. All profits, i.e. $R_{t}\left(T_{t}+I_{t}\right)$, made from lending activity are returned to households at the end of the period.

\subsection{The monetary authority}

The sole purpose of the central bank is to provide money to the economy. Rather than explicitly modeling monetary policy, we assume that the money supply grows exogenously 
at the rate, $g_{t}$. That is, the evolution of the money supply, $\bar{M}_{t}$, is given by:

$$
\bar{M}_{t}=\bar{M}_{t-1}\left(1+g_{t}\right)
$$

We assume that the growth rate follows a discrete state Markov process. The parameters of this process are chosen to facilitate the study of time-varying uncertainty. $\quad$ Specifically, $g_{t}$ will follow a four-state Markov process with possible realizations,

$$
g_{t}=\left\{\begin{array}{l}
g_{1}=\bar{g}-\delta \\
g_{2}=\bar{g} \\
g_{3}=\bar{g} \\
g_{4}=\bar{g}+\delta
\end{array}\right.
$$

Note that since the realization of the monetary growth rate is identical in states 2 and 3 , the monetary growth rate state is not determined solely by the value of $g_{t}$. Hence, we will describe the current state as $s_{i} ; i=1,2,3,4$. The transition probability matrix is given by,

$$
\Pi=\left[\begin{array}{cccc}
\pi & \frac{1-\pi}{3} & \frac{1-\pi}{3} & \frac{1-\pi}{3} \\
\frac{1-\pi}{3} & \pi & \frac{1-\pi}{3} & \frac{1-\pi}{3} \\
\frac{1-\pi}{2} & 0 & \pi & \frac{1-\pi}{2} \\
\frac{1-\pi}{3} & \frac{1-\pi}{3} & \frac{1-\pi}{3} & \pi
\end{array}\right]
$$

The limiting or unconditional distribution of this process (given by the eigenvector of $\Pi$ associated with the eigenvalue of 1 ) is uniform, i.e. the unconditional probability of state $i$ is $p_{i}=1 / 4$. It is obvious from equation (10) that this implies that the unconditional first and

${ }^{4}$ This Markov process was used previously by Salyer and Slotsve (1993) to study the effects that timevarying uncertainty of technology shocks have on equity prices and interest rates. 
second moments of money growth are, $E\left(g_{t}\right)=\bar{g}$ and $\operatorname{Var}\left(g_{t}\right)=\delta^{2} / 2$. Also, the first-order autocorrelation of money growth is given by $\operatorname{Corr}\left(g_{t}, g_{t-1}\right)=(4 \pi-1) / 3$. Hence, whether $\pi(>,=,<) 1 / 4$ implies whether $\operatorname{Corr}\left(g_{t}, g_{t-1}\right)(>,=,<) 0$.

While the unconditional probabilities are necessary for characterizing the stationary distribution of the equilibrium in the economy, it is the conditional distribution of money growth that determines equilibrium behavior. In particular, as can be seen in equation (6), changes in the first and second moments of money growth will affect the conditional expectations that determine investment decisions (i.e. funds deposited in the banking sector) and nominal interest rates. The first and second moments conditional on the state, $s_{t}$, at time $t$, are easily characterized by,

\begin{tabular}{|ccc|}
\hline$s_{i}$ & $E\left(g_{t+1} \mid s_{t}=s_{i}\right)$ & $\operatorname{Var}\left(g_{t+1} \mid s_{t}=s_{i}\right)$ \\
\hline \hline 1 & $\bar{g}-\delta \frac{(4 \pi-1)}{3}$ & $\frac{2}{9}\left(1+7 \pi+8 \pi^{2}\right) \delta^{2}$ \\
2 & $\bar{g}$ & $\frac{2}{3}(1-\pi) \delta^{2}$ \\
3 & $\bar{g}$ & $(1-\pi) \delta^{2}$ \\
4 & $\bar{g}+\delta \frac{(4 \pi-1)}{3}$ & $\frac{2}{9}\left(1+7 \pi+8 \pi^{2}\right) \delta^{2}$ \\
\hline
\end{tabular}

Consequently, the effects of the first moments of money growth on equilibrium can be studied by comparing the equilibrium properties between states $s_{1}$ and $s_{4}$. However, more important for our purposes, equilibrium behavior between states $s_{2}$ and $s_{3}$ reflects the impact of changes in the second moment of money growth since the conditional distribution in state $s_{3}$ represents a mean-preserving spread in the distribution relative to that in state $s_{2}$. Since our interest lies in studying the effects of time varying uncertainty of monetary policy, we 
will focus exclusively on equilibrium in these two states.

\section{Equilibrium}

Equilibrium in the economy is characterized by the sequence of consumption, labor, and interest rates that satisfy the necessary conditions given in the previous section and are consistent with market clearing. Market clearing in the goods market requires:

$$
c_{t}=h_{t}^{1-\alpha}
$$

Equilibrium in the lending market, the assumption that the cash-in-advance constraint is binding, and the equilibrium condition $M_{t}=\bar{M}_{t}$ imply

$$
\begin{gathered}
T_{t}+I_{t}=L_{t}=W_{t} h_{t} \\
P_{t} c_{t}=M_{t-1}+W_{t} h_{t}-I_{t}=M_{t-1}+T_{t}=M_{t-1}\left(1+g_{t}\right)=M_{t}
\end{gathered}
$$

To compute equilibrium, the following functional form for preferences is used: ${ }^{5}$

$$
U\left(c_{t}, 1-h_{t}\right)=\frac{c_{t}^{1-\gamma}}{1-\gamma}+A\left(1-h_{t}\right)
$$

where it is assumed that $\gamma \geq 1$ and $A>0$. Using this functional form, equilibrium in the labor market implies:

$$
A c_{t}^{\gamma}=\frac{W_{t}}{P_{t}}=(1-\alpha) \frac{h_{t}^{-\alpha}}{R_{t}}
$$

5 These preferences are a departure from that studied in Christiano, Eichenbaum, and Evans (1997). They use preferences that are logarithmic in a composite good represented as a non-linear function of consumption and leisure. Their functional form highlights agents' labor supply elasticity. Since our interest is in time-varying changes in risk, we impose constant relative risk aversion on consumption so that we can examine the effects of risk aversion on equilibrium behavior. 
Finally, the intertemporal necessary condition is:

$$
E_{t-1}\left[\frac{1}{c_{t}^{-\gamma} P_{t}}-R_{t} \beta E_{t}\left(\frac{1}{c_{t+1}^{-\gamma} P_{t+1}}\right)\right]=0
$$

Due to the sequential revelation of information, consumption, labor and interest rates will, in a stationary equilibrium, be a function of both the current and the previous realization of the monetary growth rate. The investment decision, in contrast, will only be a function of the monetary growth rate at time $t-1$ since this determines the relevant information set. We define a stationary monetary equilibrium in terms of the beginning of period money stock, $M_{t-1}$. That is, the investment decision is written as:

$$
i_{t}=i_{i}=\frac{I_{t}}{M_{t-1}}
$$

where $i=1,2,3,4$ denotes the state (i.e. the realization of the monetary growth rate state) in period $t-1$.

Note that the ratio of funds in the labor and goods market can be expressed as:

$$
\frac{W_{t} h_{t}}{P_{t} c_{t}}=\frac{T_{t}+I_{t}}{M_{t-1}\left(1+g_{j}\right)}=\frac{M_{t-1}\left(g_{j}+i_{i}\right)}{M_{t-1}\left(1+g_{j}\right)}=\frac{\left(g_{j}+i_{i}\right)}{\left(1+g_{j}\right)}
$$

where $j=1,2,3,4$ denotes the state of the monetary growth rate state at time $t$. Using the labor-leisure necessary condition in the left hand side of equation (15) and given the production function in (1), the left-hand side term can be written as:

$$
A c_{i j}^{\gamma-1} h_{i j}=A h_{i j}^{\gamma(1-\alpha)+\alpha}
$$

so that, in equilibrium, the ratio of funds in the lending and goods market implies the 
following 16 equations:

$$
A h_{i j}^{\gamma(1-\alpha)+\alpha}=\frac{\left(g_{j}+i_{i}\right)}{\left(1+g_{j}\right)} ; i, j=1,2,3,4
$$

By using the cash-in-advance constraint and the production function, the intertemporal necessary condition (6) can be written as:

$$
E_{i}\left[\frac{h_{i j}^{(1-\alpha)(1-\gamma)}}{1+g_{j}}-\frac{R_{i j}}{\left(1+g_{j}\right)} \beta E_{j}\left(\frac{h_{j k}^{(1-\alpha)(1-\gamma)}}{1+g_{k}}\right)\right]=0
$$

where $k=1,2,3,4$ is used to denote the state in period $t+1$. Equation (20) implies an additional 4 equations that must be satisfied in equilibrium.

Finally, equilibrium in the labor market, given by equation (15), generates the final 16 equations defining equilibrium:

$$
R_{i j}=\frac{(1-\alpha)}{T} h_{i j}^{-[\gamma(1-\alpha)+\alpha]}
$$

Equilibrium is thus characterized by the 36 values $\left(h_{i j}, R_{i j}, i_{i}\right)$ that solve the 36 equations represented by expressions (19), (20), and (21).

To explore the implications that time-varying monetary uncertainty has on interest rates, we introduce three other bonds into this economy - a one period real bond (denominated in units of consumption) and one- and two-period nominal bonds. The (gross) yields on these bonds are: $\left(\rho_{t}, R_{t}^{I}, R_{t}^{I I}\right)$. These bonds trade in an asset market that is assumed to open after the current monetary growth rate is known. Consequently, the yield on the one period nominal bond $\left(R_{t}^{I}\right)$ is differentiated from $R_{t}$ (the one-period yield on funds placed in the banking sector) because all uncertainty about liquidity has been resolved. By comparing 
the equilibrium behavior of these one-period yields, the effects of liquidity and uncertainty can be studied. The pricing formulas for the three bonds are determined by the associated necessary conditions:

$$
\begin{gathered}
U_{c, t}=\rho_{t} \beta E_{t}\left[U_{c, t+1}\right] \\
\frac{U_{c, t}}{P_{t}}=R_{t}^{I} \beta E_{t}\left(\frac{U_{c, t+1}}{P_{t+1}}\right) \\
\frac{U_{c, t}}{P_{t}}=\left(R_{t}^{I I}\right)^{2} \beta E_{t}\left(\frac{U_{c, t+1}}{P_{t+1}} \frac{1}{R_{t+1}^{I}}\right)
\end{gathered}
$$

Finally, we compute the holding premia to study the implications for term premia, i.e., the difference between the expected return from selling a two-period bond after one-period and the current one-period yield. Since there are two one-period yields in this economy, there will be two associated term premia. These are calculated as follows:

$$
\begin{aligned}
& T P_{t}=E_{t}\left[\frac{\left(R_{t}^{I I}\right)^{2}}{R_{t+1}}\right]-R_{t} \\
& T P_{t}^{I}=E_{t}\left[\frac{\left(R_{t}^{I I}\right)^{2}}{R_{t}^{I}}\right]-R_{t}^{I}
\end{aligned}
$$

We now describe the equilibrium behavior of these yields and yield differentials.

\subsection{Characterizing Equilibrium}

In order to study the equilibrium characteristics of the economy, the parameter values describing tastes $(\beta, \gamma, A)$, technology $(\alpha)$ and monetary policy $(\pi, \bar{g}, \delta)$ must be specified. The parameter values were calibrated to produce reasonable outcomes that would highlight the qualitative characteristics of equilibrium. Specifically, agents' discount factor was set to $\beta=0.95$ while the elasticity of output with respect to labor was held constant at $64 \%$ 
$(\alpha=0.36)$. In addition, the unconditional mean and standard deviation of monetary growth were set at $E\left(g_{t}\right)=\bar{g}=0.04$; and $\sqrt{2}\left(\sigma_{g}\right)=\delta=0.12$. These parameter values imply that the steady-state (i.e. no uncertainty) nominal interest rate is roughly $9 \%$.

We conducted four experiments that differed by the degree of persistence in money growth and by the degree of relative risk aversion. Specifically, we computed the equilibrium for $\pi=0.25,0.81$ which, given the Markov process specified in (11), implies that $\operatorname{Corr}\left(g_{t}, g_{t+1}\right)=$ $0,0.75$. The risk aversion parameter takes on the values $\gamma=1,5$. Finally, the parameter $A$ was adjusted so that, for all experiments, $40 \%$ of time was spent in work activity in steadystate.

Before examining the effects of time-varying uncertainty in the monetary growth rate, it is important to first note that equilibrium is indeed influenced by changes in liquidity. This can be seen in equation (19) in which the right-hand side is an increasing function in both $i_{i}$ and $g_{j}$; given that $\alpha<1$, this implies that labor will be positively related to both terms. The effect on interest rates can be seen by noting that

$$
\frac{\left(W_{t} / P_{t}\right) h_{t}}{c_{t}}=\frac{(1-\alpha) h_{t}^{1-\alpha}}{R_{t} c_{t}}=\frac{(1-\alpha)}{R_{i j}}=\frac{g_{j}+i_{i}}{1+g_{j}}
$$

Consequently, greater liquidity will cause the short-term nominal interest rate to fall.

The effects of time-varying uncertainty in money growth are now examined in the four economies by comparing equilibrium values in states $s_{2}$ and $s_{3}$. Since equilibrium interest rates and labor are determined by both the current and previous monetary growth rate states, we assume that these states are constant. That is, the low uncertainty state is represented by the values $\left(i_{2}, h_{22}, R_{22}, \rho_{22}, R_{22}^{I}, R_{22}^{I I}\right)$ while the effects of greater uncertainty 
of future money growth is reflected in the values $\left(i_{3}, h_{33}, R_{33}, \rho_{33}, R_{33}^{I}, R_{33}^{I I}\right)$. These values are reported in Tables $1 \mathrm{a}$ and Table $1 \mathrm{~b}$.

Consider first the case where there is no serial correlation in money growth, i.e., $\pi=0.25$. Note that increases in uncertainty (corresponding to $s_{t}=s_{3}$ ) result in an increase in the amount of funds placed in the banking sector. This increase in liquidity results in a fall in the short-term nominal interest (i.e. $R_{33}<R_{22}$ ) which, in turn, produces a (small) increase in labor. While relative risk aversion affects the level of interest rates, it does not affect the qualitative effects of uncertainty.

Like the short-term interest rate, all other yields (both nominal and real) fall with increases in uncertainty. This effect, however, is not due to increased liquidity but is due to the fact that both the agent's marginal utility and the inverse of the inflation rate (which determines the real return on nominal bonds) are convex functions. A mean preserving spread in the distribution causes the expected value of these functions to increase which results in lower yields.

The intuition behind these results is clear. Consider the real interest rate, $\rho_{t}$. Greater uncertainty of future consumption lowers the certainty equivalent level of next period's consumption implying an increase in the relative amount of current consumption. The price of current consumption relative to future consumption, the real interest rate, therefore falls. Again, relative risk aversion does not affect this qualitative response. With serial correlation in money growth, these qualitative effects are still present but are smaller in magnitude. 
Turning to the predictions for the term premia, note that the term premium defined in terms of $R_{t}$ (i.e. $T P_{t}$ ) always increases with greater uncertainty. However, the term premium $T P_{t}^{I}$ does not exhibit such monotonic behavior - with low risk aversion, this term premium stays relatively constant when there is no serial correlation in the growth rate (namely $\pi=0.25)$ or falls when the money growth rate is serially correlated $(\pi=0.81)$. However, with high risk aversion, the relationship is reversed: this term premium increases when money growth is serially uncorrelated (and also when uncertainty increases) but remains relatively constant when money growth is serially correlated, irrespective of the level of uncertainty.

These results can be summarized as follows: greater monetary uncertainty leads to lower interest rates. The effect on the term premia depends on whether the short term interest rate is affected primarily by liquidity or expected inflation. If liquidity factors are dominant $\left(T P_{t}\right)$, then the term premia should increase with greater uncertainty. If inflationary expectations are the primary factor affecting nominal interest rates, then the model's predictions are less clear: greater uncertainty should lower term premia if agents have low risk aversion; if risk aversion is high, term premia should increase instead.

\section{Measuring the Response of Interest Rates to Uncer- tainty}

Perhaps the most common tool of empirical analysis in the monetary economist's belt is the vector autoregression (VAR). Albeit not without controversy, VARs are commonly used to identify monetary policy shocks and to investigate the dynamic response of macro-variables

to a monetary impulse. In a related paper, Evans and Marshall (1998) analyze how these 
monetary impulses affect the shape of the yield curve for nominally risk-free bonds. In particular, they find that a contractionary shock causes a substantial increase in shortterm nominal yields, with a progressively smaller response as the maturity of the bond is lengthened. This in turn flattens the slope and the curvature of the yield curve. These observations are broadly consistent with the predictions of a limited participation model that is closely related to the model presented in Section 2. Although we investigate a different effect - that of time-varying uncertainty in monetary policy on risk-free interest rates and term premia - it will be advantageous to examine these issues with an empirical framework similar to that in Evans and Marshall (1998). In addition, the specification in Evans and Marshall (1998), originally proposed by Christiano, Eichenbaum and Evans (1996), has been used in other contexts as well (e.g. see Hamilton and Jordá, 2000; and Hoover and Jordá, 2001).

The overall empirical strategy that we pursue consists of identifying a monetary shock series based on Evans and Marshall's (1998) monetary VAR. These orthogonalized innovations allow us to then construct a series for the conditional standard deviation based on a GARCH $(1,1)$ process. We will interpret this conditional standard deviation as a measure of time-varying uncertainty in monetary policy. Finally, in order to investigate the effects that monetary uncertainty has on the yields and term premia of short-term risk-free bonds, we investigate the dynamic response of the federal funds, the three-month T-Bill and the six-month T-Bill rates to variations in time-varying uncertainty measured by the GARCH $(1,1)$ conditional standard deviation. We present the details of this empirical strategy below. 


\subsection{Identifying Policy Shocks}

The first step of the empirical analysis requires that we compute a measure of monetary policy uncertainty. A reasonable indicator of this uncertainty measure can be constructed from the conditional variance of the orthogonalized innovation to the monetary policy indicator. In particular, consider a version of Evans and Marshall's (1998) monetary VAR, which consists of a six variable system that contains the following variables: the logarithm of nonagricultural employment, EM; the logarithm of personal consumption expenditures deflator (1996= 100), $P$; the annual growth rate of the index of sensitive commodities price index, $P C O M$; the federal funds rate, $F F$; the ratio of nonborrowed reserves plus extended credit to total reserves, $N B R X$; and the annual growth rate of $\mathrm{M} 2, \Delta M 2$. Given this six variable system, Evans and Marshall (1998) follow much of the literature in taking $F F$ as the monetary policy indicator. ${ }^{6} \quad$ Therefore, we can interpret the equation for $F F$ as a reduced form for the policy reaction function.

Identification of the monetary policy shock from the policy reaction function further requires that we make an assumption that renders the residuals of the six variable VAR orthogonal to each other in a manner that also delivers a structural interpretation of such shocks. The standard assumption in the literature is to assume a Wold causal order and use the Cholesky decomposition to obtain the appropriate orthogonalization. The ordering used in Evans and Marshall (1998) is $E M_{t}, P_{t}, P C O M_{t}, F F_{t}, N B R X_{t}, \Delta M 2_{t}$. In addition, Evans and Marshall (1998) experiment with two alternative identification schemes: a nonrecursive

\footnotetext{
${ }^{6}$ The VAR literature contains numerous specifications in which the federal funds rate is chosen as the monetary policy indicator. For an extensive survey see Christiano, Eichenbaum and Evans (1999).
} 
identification strategy due to Sims and Zha (1998), and an identification strategy based on long-run restrictions due to Gali (1992). Each of these variants does not deliver significantly different responses to the orthogonalized monetary shock and thus, for the sake of brevity, will not be explored here.

The VAR is estimated with monthly data for the period 1965:1 to 1999:4 and contains twelve lags. This specification replicates that in Evans and Marshall (1998) except that it expands the sample with 40 additional observations. Figure 1 displays the responses of the variables in the system to a one standard deviation monetary policy shock (i.e., a shock to the federal funds rate equation), along with Monte-Carlo, two standard-deviation, error bands. The responses displayed in Figure 1 correspond rather closely to those reported in Figure 1, page 59 in Evans and Marshall (1998): a contractionary shock in $F F$ induces a significant decline in employment and prices. The response of $N B R X$ is consistent with a liquidity effect and the negative response of $\Delta M 2$ is consistent with the contraction of money demand. Altogether, these are conventional results in the monetary literature (see Christiano, Eichenbaum, and Evans, 1999).

\subsection{Measuring Policy Uncertainty}

A natural estimate of policy uncertainty can be obtained from the conditional variance of the orthogonalized monetary policy shocks. In the parlance of the VAR literature, these residuals represent that component of monetary policy that is unexpected by rational agents. It is therefore logical to interpret the variance of these residuals as a measure of policy uncertainty: in the limit, if the central bank were to follow a publicly announced policy rule 
precisely, there would not be any policy uncertainty and therefore, this variance would be zero. Consequently, we will collect the series of orthogonalized monetary innovations and we will fit a $\operatorname{GARCH}(1,1)$ model in order to compute the conditional variance series. More specifically, let $\varepsilon_{t}^{f f}$ denote the series of Cholesky orthogonalized monetary shocks, then the estimated model is:

$$
\sigma_{t}^{2}=\underset{(0.002)}{0.004}+\underset{(0.031)}{0.162}\left(\varepsilon_{t-1}^{f f}\right)^{2}+\underset{(0.0390)}{0.826} \sigma_{t-1}^{2}
$$

with $\log$-likelihood, $L=-155.611$ and standard errors in parenthesis. Note that the sum of the coefficients in the GARCH terms is 0.988 , suggesting a nearly integrated process. Clues that justify this high level of persistence can be obtained by graphing the conditional standard deviation series, $\widehat{\sigma}_{t}$, which can be easily constructed from the estimates in (27) and is displayed in Figure 2. We have divided the display into three parts corresponding to the chairmanships of Arthur Burns and William Miller (the pre-Volcker period); Paul Volcker (Volcker period) and Alan Greenspan (Greenspan period). Perhaps the most significant event in the graph is the dramatic increase in volatility that coincided with Volcker's first few months in office and the nonborrowed reserves targeting experiment during which the federal funds rate was allowed to fluctuate. Outside of this period of unusual volatility, there is a substantial decline (close to one-third in size) in volatility between the pre-Volcker period and Greenspan's chairmanship.

These results are broadly consistent with the evolution of monetary operating procedures and the relative transparency with which Fed policy has been communicated to the public. 
Thus, while "Temporary operations were scrutinized [by Fed watchers] to determine whether the Desk ${ }^{7}$ might be signaling a change in the stance of monetary policy ... Beginning in the late 1980's, as the FOMC ${ }^{8}$ gave increasing weight to the behavior of the federal funds rate in setting policy, reading the stance of policy became easier as it was over most of the preceding decade" (Meulendyke, 1998, page 204). Furthermore, "In 1994, when the FOMC began to issue press releases announcing policy changes almost immediately after the decisions were made, Fed watchers no longer needed to provide analysis of daily Desk activity to interpret current FOMC policy," (Meulendyke, 1998, page 204).

Very broadly speaking, one could summarize these three periods in terms of operating targets and transparency. The pre-Volcker years are essentially characterized by federal funds rate targeting, an operating procedure that also defines the Greenspan years. The main difference between these two periods is perhaps the 1994 policy experiment of announcing the target publicly, a policy that possibly accounts for the observed decline in volatility between these two periods. By contrast, the Volcker years began with the nonborrowed reserves targeting experiment which was designed to unburden the Fed from the political weight of drastically increasing short-term rates to fight off inflation. Consequently, it is perhaps not surprising that this period is characterized by the highest level of volatility, in line with the desire to maintain a high level of obfuscation.

\footnotetext{
7 "Desk" refers to the Trading Desk at the Federal Reserve Bank of New York. The Desk is in charge of conducting open market operations in a manner consistent with monetary policy objectives.

${ }^{8}$ FOMC stands for Federal Open Market Committee, and is the decision body at the Federal Reserve comissioned with setting monetary policy.
} 


\subsection{Term-Structure Responses to Monetary Policy Volatility}

Ultimately, the goal of this section is to determine whether time-varying uncertainty of monetary policy negatively affects term rates in accordance with the predictions of the model presented in Section 2. The previous two subsections have permitted us to construct a measure of this time-varying uncertainty based on the orthogonalized shocks of a conventional monetary VAR and a traditional GARCH $(1,1)$ model. This measure of uncertainty matches well with the historical evolution of the operating procedures at the Federal Reserve. Therefore, it seems natural to investigate the dynamic response of term rates to time varying uncertainty by combining this measure, $\widehat{\sigma}_{t}$, with data on term rates in a vector linear dynamic system such as a VAR. More specifically, consider a system that includes $\widehat{\sigma}_{t}$ along with the federal funds rate, $F F$; the three-month T-Bill rate, $T B 3$; and the six-month T-Bill rate, TB6. The federal funds rate and the three-month T-Bill rate are the natural counterparts of the $R_{t}$ and $R_{t}^{I}$ short-term rates presented in Section 2, while the six-month T-Bill rate can be seen as a two period bond rate relative to the three-month T-Bill rate and would most closely relate to the rate $R_{t}^{I I}$.

Let $Z_{t}=\left(\widehat{\sigma}_{t}, F F_{t}, T B 3_{t}, T B 6_{t}\right)^{\prime}$ and consider a VAR for $Z_{t}$ where the shocks are orthogonalized with a Cholesky decomposition based on the same ordering in which the variables in $Z_{t}$ are reported. This VAR will be estimated with 12 lags of monthly data over the same sample (1965:1 - 1999:4) over which we estimated the VAR in Subsection 4.1. The choice of structural identification is natural given the nature of term-structure relations between rates of increasing maturity. The impulse response function of term rates to orthogonalized 
shocks in the $\widehat{\sigma}_{t}$ equation will allow us to examine the effect of time-varying uncertainty on interest rates.

Additionally, we can use the model to analyze the effect of time-varying uncertainty on term premia. In particular, the term premium between the federal funds rate and either the three-month T-Bill rate or the six-month T-Bill rate can be expressed as follows:

$$
T P_{t}^{j}=T B j_{t}-\frac{1}{j} \sum_{i=0}^{j-1} E_{t} F F_{t+i} \quad j=3,6 ;
$$

Notice that the dynamic response of $T P_{t}^{j}$ to a shock in $\widehat{\sigma}_{t}$ can be expressed as,

$$
\frac{\partial T P_{t+s}^{j}}{\partial u_{t}^{\sigma}}=E\left(T P_{t+s}^{j} \mid \widehat{\sigma}_{t}=\widehat{\sigma}_{t-1}+u_{t}^{\sigma} ; \overleftrightarrow{Z}_{t-1}\right)-E\left(T P_{t+s}^{j} \mid \widehat{\sigma}_{t}=\overleftrightarrow{Z}_{t-1}\right)
$$

where $\overleftrightarrow{Z}_{t-1}$ denotes $\left(Z_{t-1}, Z_{t-2}, \ldots\right)$. From (28), it is easy to see that,

$$
\begin{aligned}
E\left(T P_{t+s}^{j} \mid \widehat{\sigma}_{t}\right. & \left.=\widehat{\sigma}_{t-1}+u_{t}^{\sigma} ; \overleftrightarrow{Z}_{t-1}\right)= \\
E\left(T B j_{t+s} \mid \widehat{\sigma}_{t}\right. & \left.=\widehat{\sigma}_{t-1}+u_{t}^{\sigma} ; \overleftrightarrow{Z}_{t-1}\right)-\frac{1}{j} \sum_{i=0}^{j-1} E\left(F F_{t+i} \mid \widehat{\sigma}_{t}=\widehat{\sigma}_{t-1}+u_{t}^{\sigma} ; \overleftrightarrow{Z}_{t-1}\right)
\end{aligned}
$$

and similarly for $E\left(T P_{t+s}^{j} \mid \widehat{\sigma}_{t}=\overleftrightarrow{Z}_{t-1}\right)$. Noticing that

$$
E\left(z_{j t+s} \mid z_{h t}=z_{h t-1}+u_{t}^{h} ; \overleftrightarrow{Z}_{t-1}\right)-E\left(z_{j t+s} \mid ; \overleftrightarrow{Z}_{t-1}\right) \quad z_{j t}, z_{h t} \in Z_{t}
$$

is the usual definition of the impulse response function of $z_{j}$ to a shock in $z_{h}$, the dynamic response of the term premium defined in (29) can be easily computed as the difference between the contemporaneous response of $T B j_{t}$ for $j=3$ or 6 , and the average of the first $j-$ step responses of $F F_{t}$.

Figure 3 displays graphs for the responses of each rate along with Monte-Carlo, two standard-deviation, error bands, as well as the responses of the term premia for the three 
and six month T-Bill rates. All of these responses are in reference to a shock in $\widehat{\sigma}_{t}$ of size 0.055 (remember that average volatility over the pre-Volcker, Volcker, and Greenspan periods is $0.37,0.60$, and 0.26 respectively). The results displayed in Figure 3 are consistent with the predictions in Section 2. In response to an increase in uncertainty of 0.055 , all three rates significantly decline over the following 4 months by approximately 15 basis points. The response of the term premia fluctuates around 0 and therefore, do not provide discriminating information as to whether liquidity factors or inflation expectations are the dominant factors. However, this result is consistent with the predictions in Section 3: recall that in our model, high persistence in the money growth rule keeps the term premium unresponsive. Thus, the observed unresponsiveness in term premia is consistent with the substantial monetary policy inertia that characterizes the data and which has been previously investigated in the literature (e.g. see Woodford 1999, or Sack and Wieland 2000).

\section{Conclusion}

Limited participation models are perhaps the only class of dynamic equilibrium models of monetary economies whose predictions of term structure relations match the data reasonably well. Because they are capable of generating a significant liquidity effect, these models are particularly well suited to investigate the transmission of monetary policy on the term structure. The modeling tradition that characterizes these models (as well as most dynamic equilibrium models) essentially devotes undivided attention to the analysis of relations based on first moments of the stochastic processes that characterize the behavior of policy vari- 
ables. As we discuss, this restrictive analysis is largely motivated by the technical difficulties entailed in solving these models rather than by an intrinsic disinterest in higher moment effects.

The contribution of this paper is to open new ground in this modeling tradition by exploring the effects of a particularly relevant second moment effect: that of time-varying monetary policy uncertainty on term rates. Contrary to cursory intuition, we show that term rates tend to decline when monetary policy becomes more uncertain. At the short-end, this increase in uncertainty results in increased liquidity in the lending market whereas at the long-end, the convexity of consumption to money growth modifies the certainty equivalence of a dollar in the future.

The predictions of the model are well supported by the data. An initial, moderate increase in the volatility of monetary policy can cause a generalized drop in interest rates of approximately 15 basis points over the first four months after impact. Over time, however, this effect is reversed within the span of 12 months. Term premia do not appear to respond to this increase in volatility, a result that corresponds well with the predictions of our model and the observation that monetary policy has substantial inertia. 
Table 1a - The Effects of Monetary Policy Uncertainty in a Limited Participation Model

\begin{tabular}{|c|cc||cc|}
\hline \multirow{2}{*}{} & \multicolumn{4}{|c|}{ Low Relative Risk Aversion: $\gamma=1$} \\
\cline { 2 - 5 } & \multicolumn{2}{|c||}{$\operatorname{Corr}\left(g_{t}, g_{t-1}\right)=0$} & \multicolumn{2}{c|}{$\operatorname{Corr}\left(g_{t}, g_{t-1}\right)=0.75$} \\
\hline variable & $\begin{array}{c}\text { low variance } \\
\left(s_{t}=s_{t-1}=s_{2}\right)\end{array}$ & $\begin{array}{c}\text { high variance } \\
\left(s_{t}=s_{t-1}=s_{3}\right)\end{array}$ & $\begin{array}{c}\text { low variance } \\
\left(s_{t}=s_{t-1}=s_{2}\right)\end{array}$ & $\begin{array}{c}\text { high variance } \\
\left(s_{t}=s_{t-1}=s_{3}\right)\end{array}$ \\
\hline$i_{t-1}$ & 58.0 & 58.4 & 57.3 & 57.5 \\
$h_{t \mid t-1}$ & 40.8 & 41.1 & 40.4 & 40.5 \\
\hline$R_{t \mid t-1}-1$ & 7.3 & 6.7 & 8.5 & 8.1 \\
$R_{t \mid t-1}^{I}-1$ & 8.7 & 8.4 & 9.3 & 9.2 \\
$R_{t \mid t-1}^{I I}-1$ & 8.7 & 8.5 & 9.1 & 9.0 \\
$\rho_{t \mid t-1}-1$ & 4.8 & 4.5 & 5.1 & 5.1 \\
\hline$T P_{t \mid t-1}$ & 2.3 & 2.9 & 1.1 & 1.6 \\
$T P_{t \mid t-1}^{I}$ & 0 & 0 & -0.10 & -0.20 \\
\hline
\end{tabular}

Note: all variables expressed in percentages 
Table $1 b$ - The Effects of Monetary Policy Uncertainty in a Limited Participation Model

\begin{tabular}{|c|cc||cc|}
\hline \multirow{2}{*}{} & \multicolumn{4}{|c|}{ High Relative Risk Aversion: $\gamma=5$} \\
\cline { 2 - 5 } & \multicolumn{2}{|c||}{$\operatorname{Corr}\left(g_{t}, g_{t-1}\right)=0$} & \multicolumn{2}{|c|}{$\operatorname{Corr}\left(g_{t}, g_{t-1}\right)=0.75$} \\
\hline variable & $\begin{array}{c}\text { 省 } \\
\left(s_{t}=s_{t-1}=s_{2}\right)\end{array}$ & $\begin{array}{c}\text { high variance } \\
\left(s_{t}=s_{t-1}=s_{3}\right)\end{array}$ & $\begin{array}{c}\text { low variance } \\
\left(s_{t}=s_{t-1}=s_{2}\right)\end{array}$ & $\begin{array}{c}\text { high variance } \\
\left(s_{t}=s_{t-1}=s_{3}\right)\end{array}$ \\
\hline$i_{t-1}$ & 58.0 & 58.4 & 57.1 & 57.3 \\
$h_{t \mid t-1}$ & 40.2 & 40.3 & 40.0 & 40.1 \\
\hline$R_{t \mid t-1}-1$ & 7.3 & 6.6 & 8.8 & 8.5 \\
$R_{t \mid t-1}^{I}-1$ & 7.8 & 7.0 & 9.0 & 8.8 \\
$R_{t \mid t-1}^{I I}-1$ & 8.2 & 7.8 & 9.1 & 8.9 \\
$\rho_{t \mid t-1}-1$ & 4.5 & 4.2 & 5.1 & 5.0 \\
\hline$T P_{t \mid t-1}$ & 1.3 & 1.6 & 0.50 & 0.70 \\
$T P_{t \mid t-1}^{I}$ & 0.50 & 0.80 & 0.10 & 0.10 \\
\hline
\end{tabular}

Note: all variables expressed in percentages 
Figure 1 - Responses of Macroeconomic Variables to Monetary Policy Shocks

Response to Cholesky One S.D. Innovations in the Federal Funds Rate \pm 2 S.E.

Monte-Carlo Standard Errors
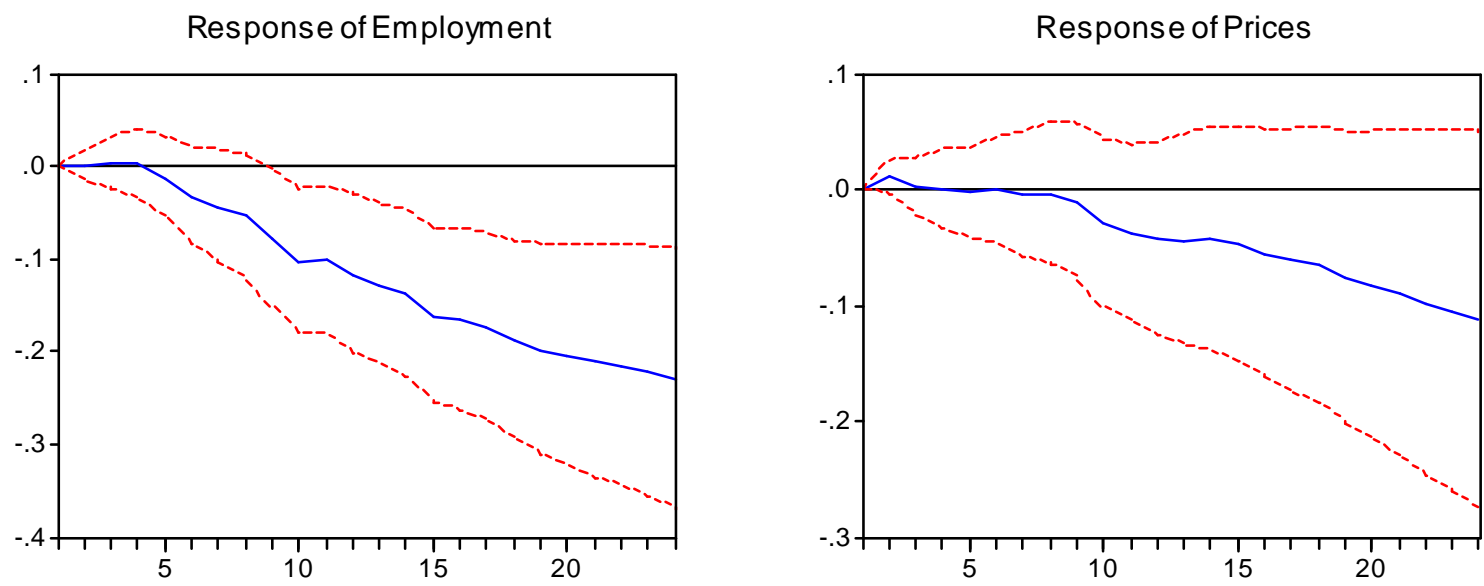

Response of Sensitive Commodity Prices

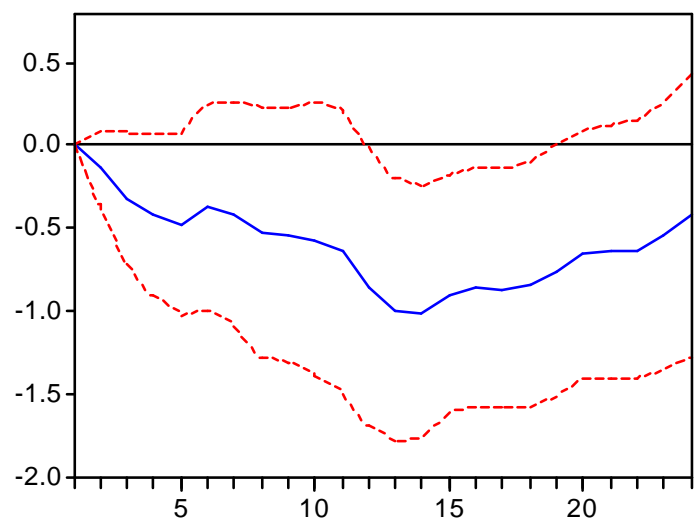

Response of Federal Funds

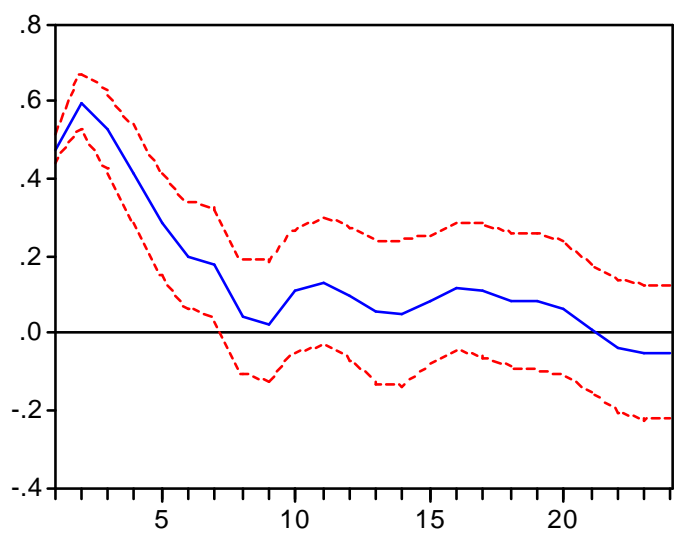

Response of Nonborrowed Reserve

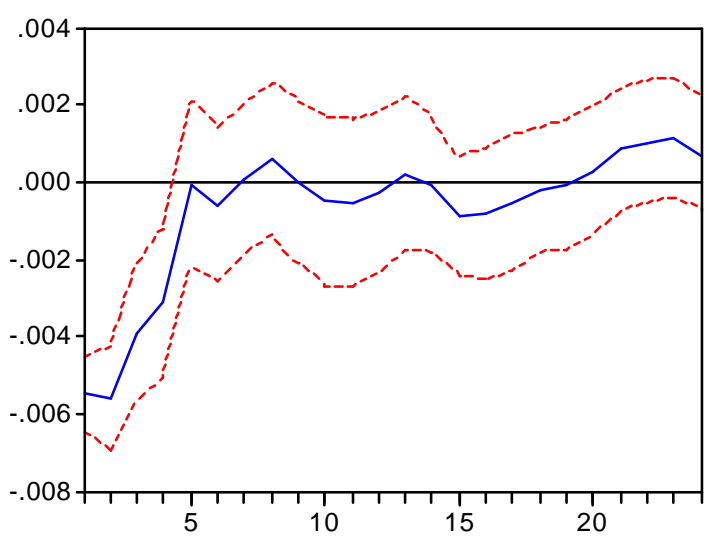

Response of M2 Growth

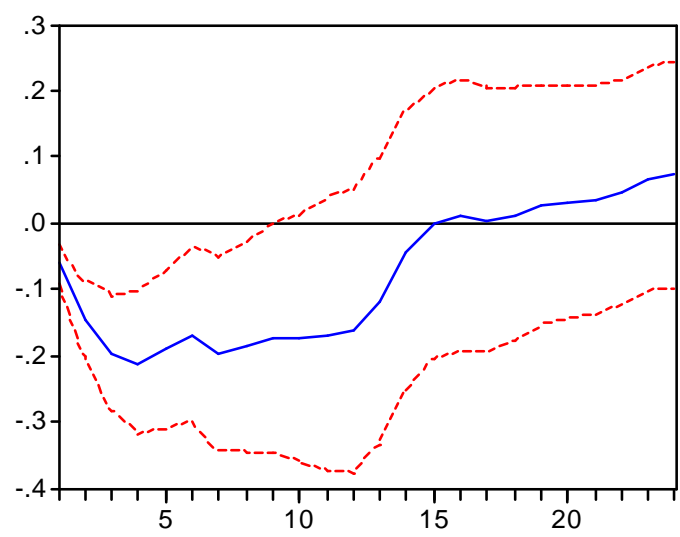


Figure 2 - Conditional Standard Deviation from $\operatorname{GARCH}(1,1)$ Model for the Orthogonalized Monetary Policy Shock

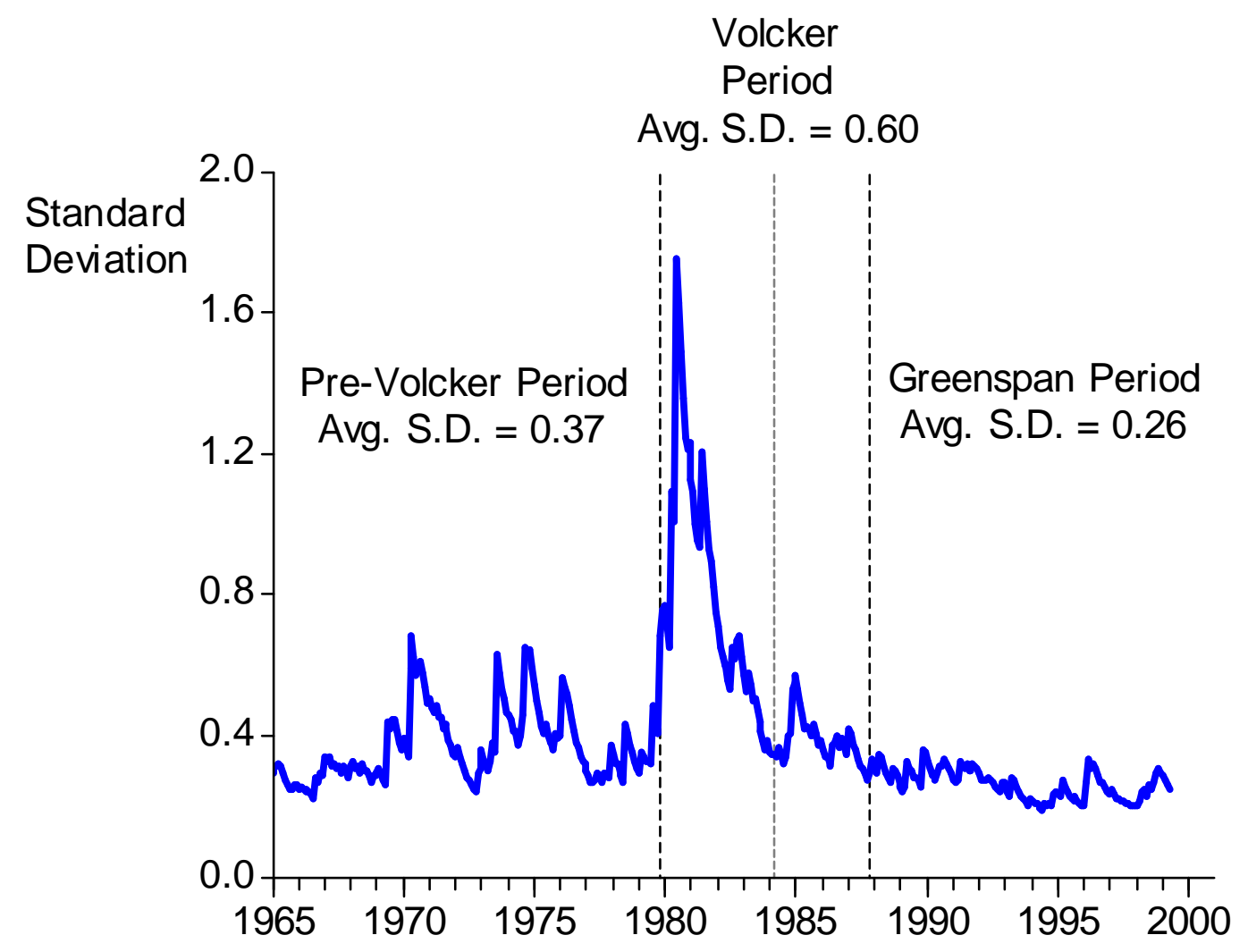


Figure 3 - Response of Term Rates and Term Premia to a 0.055 Shock in the Conditional Standard Deviation of the Monetary Policy Innovation
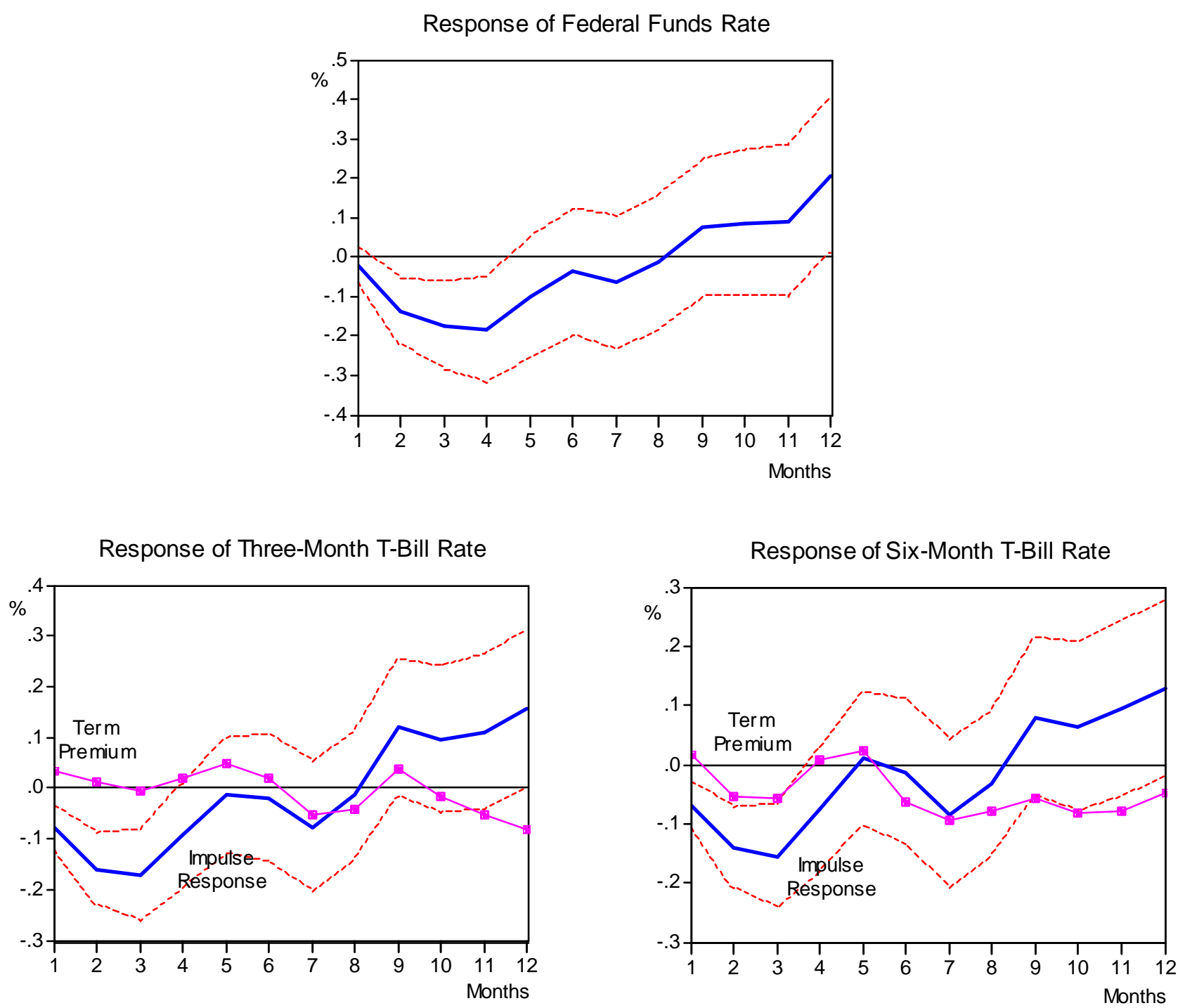

Response to Cholesky One S.D. Innovations in the Federal Funds Rate \pm 2 S.E. Monte-Carlo Standard Errors 


\section{References}

Christiano, Lawrence, Martin Eichenbaum and Charles L. Evans (1996) "Identification and the Effects of Monetary-Policy Shocks," in Financial Factors in Economic Stabilization and Growth, (eds.) M. Blejer, Z. Eckstein, Z. Hercowitz, and L. Leiderman. Cambridge: Cambridge University Press.

Christiano, Lawrence, Martin Eichenbaum, and Charles Evans (1997) "Sticky Price and Limited Participation Models of Money: A Comparison," European Economic Review, 41, 1201-1249.

Christiano, Lawrence, Martin Eichenbaum and Charles L. Evans (1999) "Monetary Policy Shocks: What Have we Learned and to What End?" in Handbook of Macroeconomics, vol. 1A, (eds.) John B. Taylor and Michael Woodford. Amsterdam: NorthHolland.

Dellas, Harris and Kevin D. Salyer (2001) "Some Fiscal Implications of Monetary Policy," Bulletin of Economic Research, forthcoming.

den Haan, Wouter (1995) "The Term Structure of Interest Rates in Real and Monetary Economics," Journal of Economic Dynamics and Control, 19, 909-940.

Evans, Charles L. and David A. Marshall (1998) "Monetary Policy and the Term Structure of Nominal Interest Rates: Evidence and Theory," Carnegie-Rochester Conference Series on Public Policy, 49, 53-111.

Gali, Jordi (1992) "How Well Does the IS-LM Model Fit Post War Data?" Quarterly Journal of Economics, 107, 709-738.

Hamilton, James D. and Oscar Jordá (2000) "A Model for the Federal Funds Rate Target," NBER Working Paper 7847.

Hodrick, Robert J. (1989) "Risk, Uncertainty, and Exchange Rates," Journal of Monetary Economics, 23, 433-460.

Hoover, Kevin D. and Oscar Jordá (2001) "Measuring Systematic Monetary Policy," Review, Federal Reserve Bank of St. Louis, forthcoming.

Lee, Sang-Sub (1995) "Macroeconomic Sources of Time-Varying Risk Premia in the Term Structure of Interest Rates," Journal of Money, Credit, and Banking, 27, 549569.

Meulendyke, Ann-Marie (1998) U.S. Monetary Policy and Financial Markets, Federal Reserve Bank of New York. 
Obstfeld, Maurice and Kenneth Rogoff (2000) "New Directions for Stochastic Open Economy Models," Journal of International Economics, 50, 117-153.

Sack, Brian and Volcker Wieland (2000) "Interest-Rate Smoothing and Optimal Monetary Policy: A Review of Recent Empirical Evidence," Journal of Economics and Business, 52(1-2), 205-228.

Salyer, Kevin D. and George Slotsve (1993) "Time-Varying Technological Uncertainty and Asset Prices," Canadian Journal of Economics, 26, 392-416.

Sims, Christopher A. and Tao Zha (1998) "Does Monetary Policy Generate Recessions?" Federal Reserve Bank of Atlanta, Working Paper, 98-12.

Woodford, Michael (1999) "Optimal Monetary Policy Inertia," Manchester School, 67(0) Supplement, 1-35. 